\title{
Changes in mental health services and suicide mortality in Norway: an ecological study
}

Håkon A Johannessen ${ }^{1 *}$, Gudrun Dieserud ${ }^{1}$, Bjørgulf Claussen² and Per-Henrik Zahl ${ }^{1}$

\begin{abstract}
Background: Mental disorders are strongly associated with excess suicide risk, and successful treatment might prevent suicide. Since 1990, and particularly after 1998, there has been a substantial increase in mental health service resources in Norway. This study aimed to investigate whether these changes have had an impact on suicide mortality.

Methods: We used Poisson regression analyses to assess the effect of changes in five mental health services variables on suicide mortality in five Norwegian health regions during the period 1990-2006. These variables included: number of man-labour years by all personnel, number of discharges, number of outpatient consultations, number of inpatient days, and number of hospital beds. Adjustments were made for sales of alcohol, sales of antidepressants, education, and unemployment.

Results: In the period 1990-2006, we observed a total of 9480 suicides and the total suicide rate declined by $26 \%$. None of the mental health services variables were significantly associated with female or male suicide mortality in the adjusted analyses ( $p>0.05$ ). Sales of antidepressants (adjusted Incidence Rate Ratio $=0.98 ; 95 \% \mathrm{Cl}=0.97-1.00$ ) and sales of alcohol (adjusted IRR $=1.41 ; 95 \% \mathrm{Cl}=1.18-1.72$ ) were significantly associated with female suicide mortality; education (adjusted IRR $=0.86 ; 95 \% \mathrm{Cl}=0.79-0.94$ ) and unemployment (adjusted $\mathrm{IRR}=0.91 ; 95 \% \mathrm{Cl}=$ 0.85-0.97) were significantly associated with male suicide mortality.
\end{abstract}

Conclusions: The adjusted analyses in the present study indicate that increased resources in Norwegian mental health services in the period 1990-2006 were statistically unrelated to suicide mortality.

\section{Background}

Suicide is a complex behavioural phenomenon in which cultural, social and psychological aspects play important roles $[1,2]$. Thus, suicide can not be reduced to a disease $[3,4]$. Still, it is well documented that several mental disorders increase the likelihood of suicide [5,6]. For example, statistics from Norway reveal that approximately $15 \%$ of all who commit suicide were in specialist mental health treatment for a psychiatric disorder at the time of death [7]. Treatment of mental disorders has therefore become a key element in suicide prevention efforts, as reflected in both international guidelines from the World Health Organization [8] and several national suicide prevention programs, including the Norwegian national plan (1994) [9].

\footnotetext{
* Correspondence: hajn@fhi.no

'Division of Mental Health, Department of Suicide Research and Prevention, Norwegian Institute of Public Health, Oslo, Norway

Full list of author information is available at the end of the article
}

In the Norwegian democratic welfare state, public authorities are responsible for providing and financing health services [10]. The municipalities are responsible for providing primary health services and the central government is responsible for providing specialised health services. By law, all Norwegian citizens have the right to necessary and adequate health treatment and care [10].

As in most industrialised countries, mental health services in Norway have been deinstitutionalised and decentralised in recent decades $[11,12]$. This process entailed a shift in primary focus from inpatient to outpatient care, grounded in the assumption that decentralised and community-based mental health services would be more caring, integrative, and therapeutically successful than traditional state hospital care [13]. Likewise, in the field of clinical suicidology, the paradigm of the hospital as a necessary part of safeguarding suicidal individuals has been increasingly questioned [14].
C Biomed Central

() 2011 Johannessen et al; licensee BioMed Central Ltd. This is an Open Access article distributed under the terms of the Creative Commons Attribution License (http://creativecommons.org/licenses/by/2.0), which permits unrestricted use, distribution, and reproduction in any medium, provided the original work is properly cited. 
Researchers from Finland reported a reduced suicide risk among psychiatric patients after the period of mental health deinstitutionalisation [15]. It has also been reported from Finland that municipalities with primarily outpatient and community-based mental health care were associated with lower suicide rates than municipalities with services primarily oriented towards providing inpatient treatment [16].

Not only were the mental health services in Norway deinstitutionalised, but the resources for mental health services were also considerably strengthened in quantitative terms in the period 1990-2006. Additionally, in 1998 the Norwegian Parliament adopted a national program calling for major investments in mental health services, to be implemented starting in 1999, with targets to be fully reached by the end of 2008 [17]. The expenditures in specialist mental health services had a real growth of 175\% from 1998-2007 [18]. In general, investments in adult psychiatric care were allocated to increase the number of health personnel with college and university education, as well as to build more decentralised psychiatric centres and to increase the quantity and quality of inpatient and outpatient care in these centres [18]. Evaluation studies have documented that the National program has had a positive impact on patients' access to mental health services $[12,18,19]$.

Recently, two ecological studies from the United States and Austria reported that the accessibility of mental health services [20] and the density of psychotherapists [21] were negatively associated with suicide rates. These findings need to be replicated. In Norway, no studies have addressed whether increased investments in mental health services over the past two decades have impacted the suicide rate.

The aim of this study was to determine whether increased mental health services resources had an impact on suicide mortality in five Norwegian health regions in the period 1990-2006.

\section{Methods}

All data used in the present study are openly available and can be downloaded at Statistics Norway and Norwegian Institute for Alcohol and Drug Research except for data on sales of antidepressants, which can be provided by the Wholesales Register in Norway upon request.

In the period 1990-2006, specialist health services in Norway were organised in five health regions. Data on suicide rates in the health regions were provided by the Causes-of-Death Registry at Statistics Norway [22]. This registry has an almost complete registration of causes of death. Causes of death were classified according to the International Classification of Diseases Ninth Revision (ICD-9) during the period 1986-1995, and according to the ICD-10 from 1996 onwards.
To measure changes in mental health services, we used available health services variables provided by Statistics Norway [23]: these were the number of beds per 1000 inhabitants (beds); the number of inpatient-days per 1000 inhabitants (bed-days); the number of discharges per 1000 inhabitants (discharges); the number of outpatient consultations per 1000 inhabitants (outpatient consultations); and the number of man-labour years by all personnel in mental health services per 1000 inhabitants. Regional figures were available from 1998 onwards. For the period before 1998, annual national figures were used.

The number of inpatient-days (that is, the number of days a patient remains in hospital) is calculated by subtracting the patient's date of discharge from the date of hospital admittance [24]. The number of beds is a calculation of accessible beds in the institutions as of 31 December each year [24]. In contrast to bed-days, the number of beds is a measure of the institutions' treatment capacity [24]. The number of discharges is the number of administrative episodes; the same patient can be discharged more than once in a year [24]. Outpatient consultations "include consultations carried out in outpatient clinics or in psychiatric institutions, giving reimbursement from the state" [24]. The total number of man-labour years is estimated as: "the number of full-time jobs and part-time jobs calculated as full-time equivalents adjusted for doctor-certified sickness absence and maternity leave" [24].

To adjust for competing explanatory variables, we used regional data on education and unemployment, and national data on sales of alcohol and sales of antidepressants, all of which are reportedly associated with suicide mortality [25-28]. In addition, we analysed for linear trends in the period 1990-2006.

Sales of pure alcohol in litres per inhabitant above the age of 15 for the whole country were provided by the Norwegian Institute for Alcohol and Drug Research [29]. The number of alcohol sales for the year 1998 was missing. The figure for this year was imputed as the average of the numbers in 1997 and 1999.

Sales of antidepressants were provided by the Wholesales Register in Norway. These data represent total sales to pharmacies and institutions. In Norway, drugs are grouped according to their Anatomical Therapeutic Chemical (ATC) classification [30]. The total national sales of ATC group N06A (antidepressants) was recorded, and the sales numbers were standardised as defined daily doses (DDD)/1000 inhabitants/day for the period 1990-2006. Sales figures of antidepressants are a proxy measure; we do not know whether these drugs were consumed by patients.

Annual regional figures of the proportion of men and women per 100 with college or university education [31], 
and annual regional figures of the proportion of men and women per 100 unemployed [32] were provided by Statistics Norway.

A power computation showed an $80 \%$ probability of detecting a reduction in the total suicide rate of $8 \%$ or more at a $5 \%$ significance level. Data were analysed by computing crude rates and Poisson regression. Separate analyses were computed for males and females. We tested each Poisson model for over-dispersion by comparing deviance with its degrees of freedom. Deviance is a measure of the discrepancy between observed and fitted values [33]. By comparing deviance with its degrees of freedom, a goodness of fit measure is provided [33]. If the goodness of fit test is significant, then the model is inappropriate [33].

We substituted missing regional data with average national data. To examine whether this procedure had unwanted bearings on the results, we fitted national models with complete data and compared the results with the regional models. In addition, to rule out the possibility of a collinearity problem, we also computed an adjusted model in which each health services variable was analysed separately.

\section{Results}

From 1990 to 2006, the total suicide rate in Norway decreased by $26 \%$ (Table 1 and Figure 1). In the same period, the number of man-labour years by all personnel, the number of discharges, and the number of outpatient consultations increased by $16 \%, 113 \%$, and $222 \%$, respectively, while the number of psychiatric hospital beds and inpatient-days declined by $42 \%$ and $43 \%$, respectively (Table 1 ). Sales of antidepressants (defined daily doses (DDD)/1000 inhabitants/day) and alcohol (pure alcohol in litres per inhabitant older than

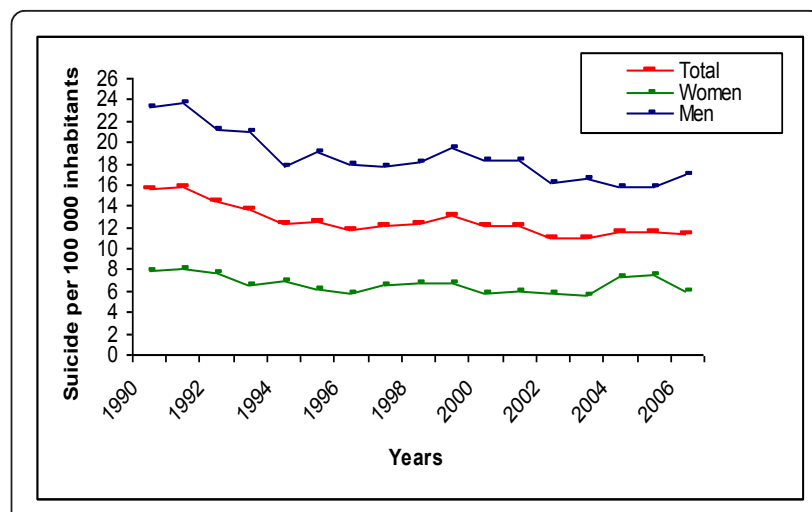

Figure 1 Suicide rate per 100000 inhabitants, by sex, in the period 1990-2006

15 years of age) increased by $353 \%$ and $29 \%$, respectively (Table 1 ). The proportion of unemployed individuals declined by $33 \%$ during this period, while the proportion of individuals with college or university education increased by $60 \%$ (Table 1 ). Regional figures are summarised in Table 2.

As Figure 1 shows, the suicide rate declined the most from 1990 to 1994 (crude annual Incidence Rate Ratio = $0.94 ; 95 \% \mathrm{CI}=0.91-0.97)$ and leveled off after that (crude annual IRR $=0.99 ; 95 \% \mathrm{CI}=0.98-1.00$ ). In contrast, the major changes in the health services variables were observed in the years 2000-2006 (Table 1).

A total of 9480 suicides distributed over the five health regions in Norway were observed during the period 1990-2006. As Tables 3 and 4 demonstrate, all variables that measured resources in specialist mental health services were unrelated to male and female suicide mortality when adjusted for competing explanatory factors $(\mathrm{p}>0.05)$.

Table 1 Changes in national suicide mortality per 100000 inhabitants

\begin{tabular}{|c|c|c|c|c|}
\hline Variables & 1990-1994 (RR) & 1995-1999 (RR) & 2000-2006 (RR) & $1990-2006$ (RR) \\
\hline Suicide mortality & $15.5-12.2(0.79)$ & $12.6-13.1(1.04)$ & $12.1-11.4(0.94)$ & $15.5-11.4(0.74)$ \\
\hline Discharges $^{1}$ & $6.2-6.9(1.11)$ & $7.5-9.2(1.23)$ & $9.9-13.2(1.33)$ & $6.2-13.2(2.13)$ \\
\hline Outpatient consultations ${ }^{1}$ & $83-122(1.47)$ & $128-148(1.16)$ & $154-267(1.73)$ & $83-267(3.22)$ \\
\hline Beds $^{1}$ & $2.4-2.0(0.83)$ & $1.9-1.7(0.89)$ & $1.7-1.4(0.82)$ & $2.4-1.4(0.58)$ \\
\hline Bed-days $^{1}$ & $774-631(0.82)$ & $617-563(0.91)$ & $545-440(0.81)$ & $774-440(0.57)$ \\
\hline Man-labour years ${ }^{1}$ & $3.98-3.83(0.85)$ & $3.88-4.09(1.05)$ & $4.13-4.61(1.12)$ & $3.98-4.61(1.16)$ \\
\hline Antidepressants $^{2}$ & $11.6-17.8(1.53)$ & $22.5-36.1(1.60)$ & $41-52.5(1.28)$ & $11.6-52.5(4.53)$ \\
\hline Alcohol $^{3}$ & $4.99-4.74(0.95)$ & $4.79-5.45(1.14)$ & $5.66-6.46(1.14)$ & $4.99-6.46(1.29)$ \\
\hline Education $^{4}$ & $12.2-14.2(1.17)$ & 14.8-16.7 (1.13) & $16.9-19.5(1.15)$ & $12.2-19.5(1.60)$ \\
\hline Unemployment ${ }^{5}$ & $5.2-5.4(1.04)$ & $4.9-3.2(0.65)$ & $3.4-3.5(1.03)$ & $5.2-3.5(0.67)$ \\
\hline
\end{tabular}

${ }^{1}$ Per 1000 inhabitants.

${ }^{2}$ Defined daily doses (DDD)/1000 inhabitants/day.

${ }^{3}$ Sales of pure alcohol in litres per inhabitant aged older than 15 years.

${ }^{4}$ College and university education per 100 aged older than 16 years.

${ }^{5}$ Unemployed per 100 (age 15-74 years).

Mortality data are accompanied by data regarding changes in explanatory variables at the national level. Rate ratios are given in parentheses. 
Table 2 Regional figures for suicide mortality per 100000 inhabitants in the period 1990-2006

\begin{tabular}{|c|c|c|c|c|c|}
\hline Variables & East region (RR) & South region (RR) & West region (RR) & Mid region (RR) & North region (RR) \\
\hline \multicolumn{6}{|l|}{ Suicide mortality } \\
\hline Men & $26.8-16.8(0.63)$ & $28.7-18.6(0.68)$ & $14.8-16.8(1.14)$ & $30.3-21.5(0.71)$ & $22.8-15.5(0.68)$ \\
\hline Women & $10.7-6.3(0.59)$ & $9.3-8.1(0.87)$ & $4.2-5.2(1.24)$ & $5.2-3.9(0.75)$ & 7.5-5.7 (0.76) \\
\hline Outpatient consultations & $145-264(1.8)$ & $131-306(2.3)$ & $125-224(1.8)$ & $138-286(2.1)$ & $155-260(1.7)$ \\
\hline Man-labour years & $4.2-5.1(1.21)$ & $3.4-3.8(1.12)$ & $4.1-4.5(1.10)$ & $3.9-4.2(1.07)$ & 4.0-4.7 (1.18) \\
\hline Discharges & $6.9-12(1.74)$ & $9.3-12.3(1.32)$ & 8.8-13 (1.48) & $9.5-13.4(1.41)$ & $9-14.8(1.64)$ \\
\hline Beds & $1.8-1.5(0.83)$ & $1.7-1.1(0.65)$ & $1.9-1.5(0.79)$ & $1.7-1.3(0.76)$ & $1.2-1.2(1.0)$ \\
\hline Bed-days & $588-479(0.82)$ & $532-347(0.65)$ & $650-472(0.73)$ & $564-385(0.68)$ & $372-368(0.99)$ \\
\hline \multicolumn{6}{|l|}{ Education } \\
\hline Men & $16.3-21.9(1.35)$ & $11.6-16.3(1.41)$ & $12.4-17.3(1.40)$ & $11.2-16.5(1.47)$ & $9.8-14.4(1.47)$ \\
\hline Women & $13.6-23.2(1.70)$ & $9.6-18.0(1.88)$ & $10.7-20.2(1.89)$ & $9.7-19.4(2.0)$ & $9.1-18.5(2.0)$ \\
\hline \multicolumn{6}{|l|}{ Unemployment } \\
\hline Men & $2.5-2.1(0.84)$ & $2.7-1.4(0.52)$ & $2.9-1.1(0.38)$ & $2.4-1.3(0.54)$ & $3.0-2.0(0.67)$ \\
\hline Women & $1.4-1.3(0.92)$ & $1.5-1.3(0.87)$ & $2.0-1.2(0.60)$ & $1.9-1.3(0.68)$ & $1.8-1.4(0.78)$ \\
\hline
\end{tabular}

Data are accompanied by regional figures for five health services variables per 1000 inhabitants in the period 1998-2006, as well as regional figures for the percentage with college and university education and regional figures of the percentage unemployed in the period 1990-2006. Rate ratios are given in parentheses.

Among women, the variables that best explained the variation in suicide mortality were health region, sales of alcohol (adjusted $\mathrm{p}=0.01$ ), and sales of antidepressants (adjusted $\mathrm{p}=0.03$ ) (Table 3$)$. The highest suicide mortality was observed in the health region 'East,' whereas health region 'Mid' (adjusted Incidence Rate Ratio = 0.68 ; $95 \% \mathrm{CI}=0.60-0.78$ ) had the lowest suicide mortality. A one-unit (one litre pure alcohol per inhabitant per year) increase in sales of alcohol predicted a $41 \%$ increase in suicide mortality (adjusted IRR $=1.41 ; 95 \%$ $\mathrm{CI}=1.18-1.72$ ), and a one-unit (one defined daily doses/1000 inhabitants/day) increase in sales of antidepressants predicted a $2 \%$ decline in suicide mortality (adjusted IRR $=0.98 ; 95 \% \mathrm{CI}=0.97-1.00)$. As can be seen by the test statistics in Table 3, the computed Poisson model had a good data fit ( $\mathrm{p}=0.27)$.

Among men, the variables that best explained the variation in suicide mortality were health region, education

Table 3 Poisson regression models of suicide mortality among Norwegian females

\begin{tabular}{|c|c|c|c|c|c|c|}
\hline \multirow[t]{2}{*}{ Variables } & \multicolumn{2}{|c|}{ Crude analysis } & \multicolumn{2}{|c|}{ Adjusted analysis I $^{1}$} & \multicolumn{2}{|c|}{ Adjusted analysis $\|^{2}$} \\
\hline & IRR $^{5}$ & $95 \% \mathrm{Cl}$ & IRR & $95 \% \mathrm{Cl}$ & IRR & $95 \% \mathrm{Cl}$ \\
\hline Year (1990-2006) & $0.99^{*}$ & $0.981-0.996$ & 1.08 & $0.912-1.289$ & 1.00 & $0.957-1.053$ \\
\hline \multicolumn{7}{|l|}{ Health region } \\
\hline East region & 1 & & 1 & & 1 & \\
\hline South region & 0.98 & $0.883-1.084$ & 0.74 & $0.301-1.831$ & 0.98 & $0.883-1.085$ \\
\hline West region & $0.71^{*}$ & $0.638-0.800$ & 0.56 & $0.300-1.058$ & $0.71^{*}$ & $0.638-0.801$ \\
\hline Mid region & $0.68^{*}$ & $0.599-0.780$ & 0.52 & $0.236-1.142$ & $0.68^{*}$ & $0.599-0.779$ \\
\hline North region & $0.79^{*}$ & $0.682-0.905$ & 0.57 & $0.234-1.400$ & $0.78^{*}$ & $0.681-0.904$ \\
\hline Outpatient consultations & 1.00 & $0.999-1.000$ & 1.00 & $0.992-1.001$ & & \\
\hline Man-labour years & 1.01 & $0.899-1.132$ & 1.00 & $0.752-1.317$ & & \\
\hline Discharges & $0.97^{*}$ & $0.952-0.988$ & 1.00 & $0.920-1.076$ & & \\
\hline Beds & $1.19^{*}$ & $1.057-1.343$ & 0.94 & $0.477-1.870$ & & \\
\hline Bed-days & $1.00^{*}$ & $1.000-1.001$ & 1.00 & $0.997-1.002$ & & \\
\hline Antidepressants & $1.00^{*}$ & 0.993-0.999 & $0.97^{*}$ & $0.944-0.992$ & $0.98^{*}$ & $0.967-0.998$ \\
\hline Alcohol & 0.95 & $0.887-1.011$ & $1.76^{*}$ & $1.222-2.543$ & $1.41^{*}$ & $1.177-1.715$ \\
\hline Education & 0.99 & $0.883-1.113$ & 0.95 & $0.776-1.153$ & & \\
\hline Unemployment & 1.00 & $0.990-1.013$ & 1.11 & $0.914-1.339$ & & \\
\hline \multirow{2}{*}{\multicolumn{3}{|c|}{$\begin{array}{l}\text { \$IRR }=\text { Incidence Rate Ratio } \\
* 0<0.05\end{array}$}} & \multicolumn{2}{|c|}{${ }^{1}$ Goodness-of-fit $\chi^{2}=80.4$} & \multicolumn{2}{|c|}{${ }^{2}$ Goodness-of-fit $\chi^{2}=84.0$} \\
\hline & & & \multicolumn{2}{|c|}{ Prob $>\chi^{2}(70)=0.19$} & \multicolumn{2}{|c|}{ Prob $>\chi^{2}(77)=0.27$} \\
\hline
\end{tabular}

Data are accompanied by secondary mental health services effect estimates adjusted for annual trends, health regions, sales of antidepressants, sales of alcohol, education, and unemployment. 
Table 4 Poisson regression models of suicide mortality among Norwegian males

\begin{tabular}{|c|c|c|c|c|c|c|}
\hline \multirow[t]{2}{*}{ Variables } & \multicolumn{2}{|c|}{ Crude analysis } & \multicolumn{2}{|c|}{ Adjusted analysis $^{1}$} & \multicolumn{2}{|c|}{ Adjusted analysis $\|^{2}$} \\
\hline & $\mathrm{IRR}^{\$}$ & $95 \% \mathrm{Cl}$ & IRR & $95 \% \mathrm{Cl}$ & IRR & $95 \% \mathrm{Cl}$ \\
\hline Year (1990-2006) & $0.98^{*}$ & $0.973-0.982$ & 1.07 & $0.988-1.159$ & 1.02 & $0.996-1.045$ \\
\hline \multicolumn{7}{|l|}{ Health region } \\
\hline East region & 1 & & 1 & & 1 & \\
\hline South region & $1.09^{*}$ & $1.025-1.163$ & $0.40^{*}$ & $0.200-0.799$ & $0.46^{*}$ & $0.299-0.717$ \\
\hline West region & $0.79^{*}$ & $0.741-0.851$ & $0.32^{*}$ & $0.176-0.580$ & $0.38^{*}$ & $0.260-0.553$ \\
\hline Mid region & $1.25^{*}$ & $1.168-1.335$ & $0.44^{*}$ & $0.212-0.907$ & $0.51^{*}$ & $0.321-0.802$ \\
\hline North region & 1.00 & $0.922-1.083$ & $0.28^{*}$ & $0.114-0.690$ & $0.33^{*}$ & $0.184-0.581$ \\
\hline Outpatient consultations & $1.00^{*}$ & $0.998-1.000$ & 1.01 & $0.998-1.003$ & & \\
\hline Man-labour years & $0.76^{*}$ & $0.709-0.818$ & 0.89 & $0.750-1.048$ & & \\
\hline Discharges & $0.96^{*}$ & $0.946-0.967$ & 1.00 & $0.950-1.056$ & & \\
\hline Beds & $1.30^{*}$ & $1.215-1.399$ & 1.15 & $0.785-1.700$ & & \\
\hline Bed-days & $1.00^{*}$ & $1.000-1.001$ & 1.00 & $0.999-1.003$ & & \\
\hline Antidepressants & $0.99^{*}$ & $0.991-0.994$ & 1.00 & $0.985-1.012$ & & \\
\hline Alcohol & $0.85^{*}$ & $0.818-0.884$ & 0.91 & $0.738-1.131$ & & \\
\hline Education & $0.98^{*}$ & $0.968-0.982$ & $0.83^{*}$ & $0.722-0.942$ & $0.86^{*}$ & $0.785-0.940$ \\
\hline Unemployment & $1.11^{*}$ & $1.075-1.147$ & $0.92^{*}$ & $0.859-0.985$ & $0.91^{*}$ & $0.849-0.966$ \\
\hline \multirow{2}{*}{\multicolumn{3}{|c|}{$\begin{array}{l}\text { \$IRR }=\text { Incidence Rate Ratio } \\
{ }^{*} \mathrm{p}<0.05\end{array}$}} & \multicolumn{2}{|c|}{${ }^{1}$ Goodness-of-fit $\chi^{2}=73.2$} & \multicolumn{2}{|c|}{${ }^{2}$ Goodness-of-fit $\chi^{2}=79.5$} \\
\hline & & & \multicolumn{2}{|c|}{ Prob $>\chi^{2}(70)=0.37$} & \multicolumn{2}{|c|}{ Prob $>\chi^{2}(77)=0.40$} \\
\hline
\end{tabular}

Data are accompanied by secondary mental health services effect estimates adjusted for annual trends, health regions, sales of antidepressants, sales of alcohol, education, and unemployment.

(adjusted $\mathrm{p}=0.01$ ), and unemployment (adjusted $\mathrm{p}=$ 0.01) (Table 4). The highest suicide mortality was observed in the region 'East', while health region 'North' $(\mathrm{IRR}=0.33 ; 95 \% \mathrm{CI}=0.18-0.58)$ had the lowest suicide mortality. A one-unit (1\%) increase in the proportion of men with college or university education predicted a $14 \%$ decline in suicide mortality (adjusted IRR $=0.86 ; 95 \%$ $\mathrm{CI}=0.79-0.94)$, and a one-unit (1\%) decline in the proportion of unemployed men predicted a $9 \%$ decline in suicide mortality (adjusted IRR $=0.91 ; 95 \% \mathrm{CI}=0.85$ 0.97 ). As can be seen by the test statistics in Table 3 , the computed Poisson model had a good data fit $(\mathrm{p}=0.40)$.

To control for a potential collinearity problem, we computed an adjusted model in which each of the five health services variables were included separately (not shown). None of the health services variables were statistically related to female or male suicide mortality (adjusted p > 0.05). We also computed a model with complete national data (not shown). None of the five mental health services variables were statistically associated with reduced suicide mortality for men or women ( $\mathrm{p}>0.05)$.

\section{Discussion}

The aim of this study was to investigate whether increased mental health services resources had an impact on suicide mortality in the five Norwegian health regions in the period 1990-2006. Although substantial changes in mental health services resources were observed (Table 1), suicide mortality in both females and males was statistically unrelated to these changes (adjusted p > 0.05) (Tables 3 and 4).

Despite the observed decline in hospital beds, the number of discharges increased by $113 \%$ during the study period; this apparent discrepancy can be explained by the decline in the average length of hospital stays [12]. The additional increase in outpatient consultations and man-labour years by all personnel indicates that more patients were treated throughout the period. It can be argued that the shortened length of stays increases the risk of incomplete recovery, and may thereby explain the excess suicide risk generally observed in the immediate post-discharge period [34]. However, the data in the present study did not indicate increased suicide risk due to reduction in inpatient days.

Several of the adjustment variables were significantly associated with suicide mortality. Among females, increased sales of antidepressants were associated with a decline in suicide mortality (adjusted $\mathrm{p}=0.03$ ), while increased sales of alcohol were associated with an increase in suicide mortality (adjusted $\mathrm{p}=0.01$ ). Among males, increased level of college and university education were associated with a decline in suicide mortality (adjusted $\mathrm{p}=0.01$ ), while reduction of unemployment was associated with a decline in suicide mortality (adjusted $\mathrm{p}=0.01)$. Crude differences in male and female suicide mortality were observed across the health regions. Among females, these differences do not change 
in the adjusted analysis; however, adjustments for educational level and the level of unemployment impact the regional differences among males. We do not know why these crude regional differences in female and male suicide mortality exist.

The present study should be interpreted with caution, because statistical associations can be masked by the fact that we may have failed to adjust for relevant confounders. Another shortcoming in the present study is that we only had one variable that directly measured the increased resources in outpatient services. Due to the process of downsizing traditional psychiatric hospitals, present mental health services policy favours active outpatient treatment. Therefore, the negative findings may be due to restricted measurements on outpatient mental health services. Further, the increased resources in child and adolescent mental health services, which were not addressed in this study, may pay off in lower suicide rates later on. Finally, it is important to be aware that associations at the individual level cannot be deduced from an ecological study design.

Our findings are in line with a recently published, cross-national, ecological study that revealed no relation between suicide rates and mental health funding, service provision, or national policies on mental health [35]. Further, in an ecological study from the United Kingdom, Lewis and co-workers [36] examined the association between standardised suicide mortality ratios and the provision of mental health services. The results demonstrated that higher quantity of provision was not negatively associated with standardised suicide mortality ratios. In addition, our findings are in line with a prospective, multi-level study from the United States, in which the researcher found no association between variation in patterns of service delivery at the system level and suicide risk [37]. However, there are ecological studies that have reported associations between various measurements of mental health services provision and suicide rates [16,20,21]. For example, Kapusta [21] and coworkers found that both sales of antidepressants and density of psychotherapists were negatively associated with suicide rates.

It is undisputable that the Norwegian mental health services have been strengthened in quantitative terms. However, little is known about the content of the treatment given and therefore the quality and effectiveness of the treatment [18]. Hence, we do not know whether more patients were successfully treated during this period. In addition, varied, interdisciplinary outpatient services that are specialised in handling suicidal patients have not been developed.

Far from all suicidal mental health patients are receiving treatments that have proven to have a preventive effect on suicide. A recent health technology assessment (review of the literature) of the effects of mental health services interventions for the prevention of suicide found that few interventions were specifically tailored to reduce suicidality [38]. Most of the studies examined in the assessment evaluated the effect of treatment related to mental illness per se. Further: "the inclusion and exclusion criteria were not always well described and in a number of studies individuals with high suicide risk were not included" [30]. This strategy, according to which suicidality is conceptualised as a symptom of mental illness and prevention of suicide requires treatment of the underlying disease, has come under increasing criticism $[14,39,40]$. An alternative strategy has been proposed, namely, a focus on suicidality as the primary clinical target, in which suicidal behaviour and its causes are addressed directly $[14,39]$. In this approach, the individual is seen as primarily suicidal with various subsymptoms of mental illness in need of treatment [14].

Because suicide is a multi-factorial phenomenon, it is also reasonable to infer that effective suicide prevention strategies must be broader than the focus on the treatment of mental disorders. For example, public health prevention strategies that have aimed at restricting suicide means [41-43], toning down media reports [44], and restricting alcohol [45] have been demonstrably successful. Multidisciplinary approaches to suicide research and prevention are needed, which require research teams with "a balanced composition between biologically and psychologically oriented investigators" [2], and there is a "need to evaluate also other concomitant factors such as socio-economic, cultural, and religious aspects" [2].

A multidisciplinary approach does not preclude the priority of suicide prevention among psychiatric patients, who constitute a group at increased risk; however, treatment ought to target suicidality more specifically.

\section{Conclusions}

Mental disorders are strongly associated with increased suicide risk. Therefore, successful treatment may prevent suicide, and a greater number of treated individuals may impact the suicide rate. In this study, we observed a substantial increase in mental health services resources in Norway during the period 1990-2006. However, the adjusted analyses indicate that these changes were statistically unrelated to female and male suicide mortality.

\section{Acknowledgements}

This study was funded by the Research Council of Norway.

\section{Author details}

'Division of Mental Health, Department of Suicide Research and Prevention, Norwegian Institute of Public Health, Oslo, Norway. ${ }^{2}$ Institute of General Practice and Community Health, Section for Social Medicine, University of Oslo, Oslo, Norway. 


\section{Authors' contributions}

HAJ made substantial contributions to the conception and design of the manuscript, drafted the manuscript, analysed and interpreted the data, and critically revised the manuscript for important intellectual content. $\mathrm{PHZ}$ made substantial contributions to the conception and design of the manuscript, analysed and interpreted the data, and critically revised the manuscript for important intellectual content. GD made substantial contributions to the conception and design of the manuscript, interpreted the data, and critically revised the manuscript for important intellectual content. BC made substantial contributions to the conception and design of the manuscript, interpreted the data, and critically revised the manuscript for important intellectual content. All authors read and approved the final manuscript.

\section{Competing interests}

The authors declare that they have no competing interests.

Received: 5 March 2010 Accepted: 28 March 2011

Published: 28 March 2011

\section{References}

1. Nordentoft M: Prevention of suicide and attempted suicide in Denmark Epidemiological studies of suicide and intervention studies in selected risk groups. Dan Med Bull 2007, 54:306-69.

2. De Leo D: Struggling against suicide: the need for an integrative approach. Crisis 2002, 23:23-31.

3. Silverman MM, Berman AL, Sanddal ND, O'carroll PW, Joiner TE: Rebuilding the tower of Babel: a revised nomenclature for the study of suicide and suicidal behaviors. Part 1: Background, rationale, and methodology. Suicide Life Threat Behav 2007, 37:248-63.

4. Silverman MM, Berman AL, Sanddal ND, O'carroll PW, Joiner TE: Rebuilding the tower of Babel: a revised nomenclature for the study of suicide and suicidal behaviors. Part 2: Suicide-related ideations, communications, and behaviors. Suicide Life Threat Behav 2007, 37:264-77.

5. Harris EC, Barraclough B: Suicide as an outcome for mental disorders - A meta-analysis. Br J Psychiatry 1997, 170:205-28.

6. Mortensen PB, Agerbo E, Erikson T, Qin P, Westergaard-Nielsen N: Psychiatric illness and risk factors for suicide in Denmark. Lancet 2000, 355:9-12.

7. Gjertsen F, Nesje I, Espeland B, Haddeland AL, Reinholdt NP, Stokkvik EH: Variation in suicide mortality across regions in Norway 1996-2006.

8. World Health Organization: Guidelines for the primary prevention of mental, neurological and psychosocial disorders. 4. Suicide. [http:// whalibdoc.who.int/hq/1993/WHO_MNH_MND_93.24.pdf].

9. The national plan for suicide prevention 1994-1998. [http://www. helsetilsynet.no/upload/Publikasjoner/skriftserien/ national_plan_suicide_prevention_ik-2539.html].

10. Mental health services in Norway. [http://www.regjeringen.no/upload/ kilde/hod/red/2005/0011/ddd/pdfv/233840-mentalhealthweb.pdf].

11. Lamb HR, Bachrach LL: Some perspectives on deinstitutionalization. Psychiatric Services 2001, 52:1039-45.

12. Pedersen $\mathrm{PB}$, Kolstad A: De-institutionalisation and transinstitutionalisation - changing trends of inpatient care in Norwegian mental health institutions 1950-2007. Int J Ment Health Syst 2009, 3:28.

13. Ministry of Health and Care Services: St meld nr 25 (1996-1997) åpenhet og helhet.Om psykiske lidelser og tienestetilbudene [Psychiatric Disorders and Health Services] Oslo; 1997.

14. Jobes DA: Collaborating to prevent suicide: A clinical-research perspective. Suicide Life Threat Behav 2000, 30:8-17.

15. Pirkola S, Sohlman B, Heila H, Wahlbeck K: Reductions in Postdischarge Suicide After Deinstitutionalization and Decentralization: A Nationwide Register Study in Finland. Psychiatr Serv 2007, 58:221-6.

16. Pirkola S, Sund R, Sailas E, Wahlbeck K: Community mental-health services and suicide rate in Finland: a nationwide small-area analysis. Lancet 2009, 373:147-53.

17. Ministry of Health and Care Services: St prop nr 63 (1999-2008) Opptrappingsplanen for psykisk helse 1999-2006 Oslo; 1998

18. Brofoss K, Larsen F: Evaluering av opptrappingsplanen for psykisk helse (2001-2009). Sluttrapport - syntese og analyse av evalueringens delprosjekter. Oslo, Norges forskningsråd [The Norwegian research Council); 2009
19. Pedersen PB, Lilleeng SE, Sitter M: Evaluering av Opptrappingsplanen for psykisk helse - supplerende analyser innen spesialisthelsetjenesten [Evaluation of the Plan of Act to Improve Mental Health and Psychiatric Services]. Trondheim, SINTEF Helse; 2009.

20. Tondo L, Albert MJ, Baldessarini RJ: Suicide rates in relation to health care access in the United States: an ecological study. J Clin Psychiatry 2006, 67:517-23

21. Kapusta ND, Niederkrotenthaler T, Etzersdorfer E, Voracek M, Dervic K, JandlJager $E$, et al: Influence of psychotherapist density and antidepressant sales on suicide rates. Acta Psychiatr Scand 2009, 119:236-42.

22. Statistics Norway. [http://statbank.ssb.no/statistikkbanken/Default_FR.asp? PXSid $=0 \&$ nvl=true\&PLanguage $=1 \&$ tilside $=$ selecttable/hovedtabellHjem asp\&KortnavnWeb=dodsarsak].

23. Statistics Norway. [http://statbank.ssb.no/statistikkbanken/Default_FR.asp? PXSid $=0 \&$ nvl=true\&PLanguage $=1 \&$ tilside $=$ selecttable/hovedtabellHjem. asp\&KortnavnWeb=speshelsepsyk]

24. Statistics Norway. [http://www.ssb.no/vis/speshelse_en/about.html].

25. Denney JT, Rogers RG, Krueger PM, Wadsworth T: Adult Suicide Mortality in the United States: Marital Status, Family Size, Socioeconomic Status, and Differences by Sex. Soc Sci Q 2009, 90:1167.

26. Bramness JG, Walby FA, Tverdal A: The sales of antidepressants and suicide rates in Norway and its counties 1980-2004. J Affect Disord 2007, 102:1-9.

27. Skog OJ, Teixeira Z, Barrias J, Moreira R: Alcohol and suicide-the Portuguese experience. Addiction 1995, 90:1053-61.

28. Stuckler D, Basu S, Suhrcke M, Coutts A, McKee M: The public health effect of economic crises and alternative policy responses in Europe: an empirical analysis. Lancet 2009, 374:315-23.

29. Sirus RusStat - rusmiddelstatistikk på nett. [http://statistikk.sirus.no/sirus/]

30. NorPD: definitions. [http://www.fhi.no/eway/default.aspx? pid=238\&trg=Area_5954\&MainLeft_5812=5954:0: \&Area_5954=5825:67872::0:5955:1 $\cdots 0: 0]$.

31. Statistics Norway. [http://statbank.ssb.no/statistikkbanken/Default_FR.asp? Productid $=04.01 \&$ PXSid $=0 \&$ nvl=true\&Language $=1 \&$ tilside $=$ selecttable/ MenuSelP.asp\&SubjectCode=04].

32. Statistics Norway. [http://statbank.ssb.no/statistikkbanken/Default FR.asp? Productid $=06.01 \&$ XSid $=0 \&$ nvl=true\&PLanguage $=1 \&$ tillide $=$ selecttable $/$ MenuSelP.asp\&SubjectCode $=06]$.

33. Kuhn L, Davidson LL, Durkin MS: Use of Poisson regression and time series analysis for detecting changes over time in rates of child injury following a prevention program. Am J Epidemiol 1994, 140:943-55.

34. Johannessen HA, Dieserud G, Jakhelln F, Zahl PH, De Leo D: Changes in institutional psychiatric care and suicidal behaviour: a follow-up study of inpatient suicide attempters in Baerum, Norway. Soc Psychiatry Psychiatr Epidemiol 2009, 44:845-51.

35. Shah A, Bhandarkar R, Bhatia G: The relationship between general population suicide rates and mental health funding, service provision and national policy: a cross-national study. Int I Soc Psychiatry 2010, 56:448-53.

36. Lewis G, Appleby L, Jarman B: Suicide and psychiatric services. Lancet 1994, 344:822.

37. Desai RA, Dausey DJ, Rosenheck RA: Mental health service delivery and suicide risk: The role of individual patient and facility factors. Am J Psychiatry 2005, 162:311-8.

38. Prevention of suicide. Part 1: Psychotherapy, drug treatment and electroconvulsive treatment. [http://www.kunnskapssenteret.no/ Publikasjoner $/ 534$. cms? onepage $=1]$.

39. Linehan MM: Suicide intervention research: a field in desperate need of development. Suicide Life Threat Behav 2008, 38:483-5.

40. Rudd MD: The suicidal mode: a cognitive-behavioral model of suicidality. Suicide Life Threat Behav 2000, 30:18-33.

41. Hawton K, van Heeringen K: Suicide. Lancet 2009, 373:1372-81.

42. Kapusta ND, Etzersdorfer E, Krall C, Sonneck G: Firearm legislation reform in the European Union: impact on firearm availability, firearm suicide and homicide rates in Austria. Br J Psychiatry 2007, 191:253-7.

43. Leenaars AA, Moksony F, Lester D, Wenckstern S: The impact of gun control (Bill C-51) on suicide in Canada. Death Stud 2003, 27:103-24

44. Etzersdorfer E, Sonneck G: Preventing suicide by influencing mass-media reporting. The Viennese experience 1980-1996. Archives of Suicide Research 1998, 4:67-74. 
45. Wasserman D, Varnik A: Suicide-preventive effects of perestroika in the former USSR: the role of alcohol restriction. Acta Psychiatr Scand Suppl 1998, 394:1-4

\section{Pre-publication history}

The pre-publication history for this paper can be accessed here: http://www.biomedcentral.com/1472-6963/11/68/prepub

doi:10.1186/1472-6963-11-68

Cite this article as: Johannessen et al:: Changes in mental health services and suicide mortality in Norway: an ecological study. BMC Health Services Research 2011 11:68.

Submit your next manuscript to BioMed Central and take full advantage of:

- Convenient online submission

- Thorough peer review

- No space constraints or color figure charges

- Immediate publication on acceptance

- Inclusion in PubMed, CAS, Scopus and Google Scholar

- Research which is freely available for redistribution

Submit your manuscript at www.biomedcentral.com/submit
C) Biomed Central 